\title{
Contemporary Pastoralism in the Dhofar Mountains of Oman
}

\author{
Lawrence Ball $^{1}$ (D) Douglas MacMillan ${ }^{2} \cdot$ Joseph Tzanopoulos $^{2} \cdot$ Andrew Spalton $^{3} \cdot$ Hadi Al Hikmani $^{4} \cdot$ Mark Moritz $^{5}$
}

Received: 19 December 2019 / Revised: 31 March 2020 / Accepted: 22 April 2020 / Published online: 12 May 2020

(C) The Author(s) 2020

\begin{abstract}
In the Dhofar Mountains of Oman stakeholders are concerned about the social and ecological sustainability of pastoralism. In this study we used interviews with pastoralists to examine the prevailing drivers of pastoralism and how they are changing. We find that people are committed to pastoralism for sociocultural reasons but also that this commitment is under pressure because of husbandry costs and changing values. We find that capital investment in feedstuff enables pastoralists to overcome the densitydependent regulation of livestock populations. However, high production costs deter investment in marketing and commercialization, and there is little off take of local livestock. Our study reveals how pastoral values, passed down within households, motivate pastoralists in the face of high husbandry costs, modernization and social change.
\end{abstract}

Keywords Arabia $\cdot$ Pastoral values $\cdot$ Supplementary feed $\cdot$ Camels $\cdot$ Overgrazing $\cdot$ Dhofar Mountains $\cdot$ Oman

\section{Introduction}

Pastoral systems are under pressure in many parts of the world due to globalization, modernization, marketization, land use and tenure change, population growth, and climate change (Nyberg et al. 2015; Robinson et al. 2011; Sayre et al. 2013; Watson et al. 2016). Nonetheless, many pastoralists remain committed to livestock-based livelihoods. Understanding the drivers of smallholder livestock production systems will help assess and improve their social and ecological sustainability in the future.

The last century saw major changes in pastoral systems in many Middle East and North African countries, largely due to detribalization, deterritorialization, and sedentarization processes driven by government efforts to modernize nomadic

Lawrence Ball

bal1.2174@osu.edu

Douglas MacMillan

d.c.macmillan@kent.ac.uk

Joseph Tzanopoulos

j.tzanopoulos@kent.ac.uk

Andrew Spalton

jandrewspalton@gmail.com

Hadi Al Hikmani

hadidofar@gmail.com

Mark Moritz

moritz.42@osu.edu peoples (Chatty 2006). However, in the oil-rich gulf states of the Arabian Peninsula, pastoralist livelihoods were supported through subsidised supplementary feed and rural infrastructure development (Gardner 2004). Relative to other pastoral systems across the globe, contemporary pastoralism in the Arabian Peninsula is understudied even though it may be considered less sustainable due to factors such as greater climatic variability, higher soil salinity, greater feedstuff provisioning, and low market participation (Peacock et al. 2003). Furthermore, new research is required on a regular basis due to the rapid economic development, modernisation, and social change occurring in these small oil-rich gulf nations.

Today, extensive forms of pastoralism in the Arabian Peninsula are mainly limited to rangelands in Oman and the Kingdom of Saudi Arabia, where vehicles are used to

1 Department of Evolution, Ecology and Organismal Biology, The Ohio State University, Columbus, OH 43210, USA

2 Durrell Institute of Conservation and Ecology, School of Anthropology and Conservation, University of Kent, CT27NR Canterbury, UK

3 Office of the Minister, Diwan of Royal Court, Muscat, Oman

4 Office for Conservation of the Environment, Diwan of Royal Court, Salalah, Oman

5 Department of Anthropology, The Ohio State University, Columbus, OH 43210, USA 
transport livestock, water, and feedstuffs (Hamadeh 2014). Throughout Arabia, trucks have replaced camels for transport, and with the integration of rural people into the market economy many pastoralists have shifted to more profitable livestock such as sheep (Chatty 2013; Degen et al. 2019; Gardner 2004). The Dhofar Mountains in Oman are one of few places in the Arabian Peninsula where an extensive form of camel pastoralism persists, although camel ownership as a secondary income, hobby, or for competitions is common elsewhere in Oman and in other oil rich Gulf nations (Gallacher 2010). Globally, camel numbers are increasing, but growth rates differ substantially among countries (Faye 2014).

In the Dhofar Mountains of Oman people have remained committed to pastoralism, and livestock populations have increased substantially since the 1970s. Over the 30-year period from 1982 to 2012, the cattle, camel, and goat populations in Dhofar increased by at least $257 \%, 170 \%$ and $96 \%$ respectively (Spalton 2020). Stakeholders, including scientists (Janzen 2000), government officials (Directorate-General of Nature Conservation 2010), and pastoralists themselves (El-Mahi 2011a) are concerned about the ecological impacts of growing livestock populations. A recent assessment of the impacts of livestock browsing on woody vegetation in western Dhofar, found lower species diversity and plant density, higher frequencies of unpalatable species, and altered phytomorphology under higher stocking rates (Ball and Tzanopoulos 2020). The fact that pastoralists rely on supplementary feed for most of the year indicates insufficient forage resources and overstocking since the 1970s. Numerous reports and action plans have included objectives to relieve pressure on the rangelands (e.g., GRM International 1982; UNEP 2005; WS Atkins International 1990), however, recommendations such as commodification, zoning, and reforestation have not been implemented (Whitcombe 1998).

In order to assess the sustainability of pastoralism in Dhofar we need to understand the social factors driving it. Therefore, in this study we conducted questionnaires and interviews with pastoralists to examine the prevailing drivers of pastoralism and how these are changing.

\section{A Short History of Pastoralism in Dhofar}

The Dhofar Mountains are part of the central South Arabian mountains that span the governorates of Mahra in Yemen and Dhofar in Oman. In central and western Dhofar and eastern Mahra thick fogs and precipitation during the monsoon, popularly known as the khareef, support an endemic cloud forest community with high biodiversity and endemism (Kürschner et al. 2004). The khareef has provided forage resources for pastoralism for millennia (Petraglia and Rose 2010). However, recent research suggests that forest loss may inhibit the ecosystem's ability to intercept fog moisture during the khareef, a process thought to be critical to ecosystem functioning (Hildebrandt and Eltahir 2006) and groundwater recharge (Friesen et al. 2018).

Prior to Oman's renaissance in 1970, pastoralists in the Dhofar Mountains were mostly subsistence goat or cattle herders who lived in stone and wood houses and caves. Camel populations were small in comparison to drier areas, as camels are comparatively unsuited to the monsooninfluenced escarpments. The herders practised a transhumance system based on seasonal variation in climatic and habitat conditions and tribal land tenure institutions regulated the use of water and forage resources (Janzen 1990).

Following the Dhofar Rebellion (1962-1975) the region rapidly developed under the leadership of Oman's ruler Sultan Qaboos bin Said and with revenue from an expanding oil industry. Many pastoralists were offered government-paid employment, predominantly in the Firqat, an irregular military force. With regularly paid employment, families were quick to start acquiring higher-status livestock, namely camels. The government improved road infrastructure, installed a water supply network, constructed high-capacity livestock watering troughs, built dams at springs, and established a system of manufacturing and distributing subsidised feedstuffs. Families settled in villages close to the new amenities. Expatriate workers from South Asia were hired to carry out the everyday work of livestock husbandry. The Oman government imposed a new land tenure system that ensured that everyone had access to common-pool grazing resources, which replaced the tribal land tenure institutions. The use of four-wheel drive vehicles became widespread to transport feedstuff, water, and livestock in the state owned rangelands (El-Mahi 2011a).

These historical processes of sedentarization, detribalization, and an increased use of feedstuffs and vehicles, have occurred in other Middle Eastern and North African countries (Blench 1995; Degen et al. 2019; Louhaichi and Tastad 2010). The effects have been a shift from camels to more profitable livestock (Blench 1995; Hamadeh 2014; Sidahmed 1992) or a shift to hobbyist camel ownership (Chatty 2006; Gallacher 2010). However, pastoralists in Dhofar have remained committed to extensive forms of camel, cattle, and goat pastoralism. Here, we examine why people in Dhofar remain committed to pastoralism in the face of globalization, modernisation, and societal change.

\section{Study Area and Population}

This study was conducted in Jabal Qamar, the westernmost mountain range in Dhofar (Fig. 1), which comprises two administrative districts, the Wilayat of Dalkut (west) and the Wilayat of Rakhyut (east). There are 75 permanently inhabited villages and ten villages inhabited during the khareef, with a total human population of 7,799 . The 2015 national livestock census recorded 15,164 camels, 27,522 
head of cattle, and 14,217 goats in Jabal Qamar (NCSI 2017). Most households own at least one livestock type. Household sizes are often large with over ten members spanning several generations. Most women do not have paid employment. Most men with primary education are employed by the government at Firqat centres or in other positions such as guards and drivers for government institutions (e.g., schools, hospitals, and local government offices). Men with secondary and tertiary educations are generally in higher-earning employment such as high-ranking government positions, teachers in higher education, or owners of private businesses. Unemployment levels are high among young adults while jobs in public sector services such as restaurants and garages employ expatriate workers.

Pastoralists in Jabal Qamar follow a transhumance regime (Fig. 2) to avoid the adverse conditions caused by the khareef (El-Mahi 2011b). From mid-June to mid-September, the abundant moisture stimulates high rates of vegetative growth, mould invades property, soils become saturated, and hematophagous flies are abundant. These conditions are uncomfortable for people and considered dangerous for camels, as they can slip in the soft mud. Therefore, camels and goats are moved from the escarpments to the plateau or coastal plains, whilst cattle usually stay on the escarpments. Following the khareef (September-January) livestock are moved down the escarpments to feed on natural vegetation in addition to feedstuff. During the dry season (January-June) livestock are kept close to villages or camps and sustained primarily on feedstuff.

\section{Methods}

Two British researchers and an Omani translator conducted questionnaires and interviews with pastoralists in Jabal Qamar between April 2016 and April 2017. Four government officials and a feedstuff company manager were also interviewed. The translator was from Jabal Qamar, spoke the local language of Jibbāli and provided real-time translation.

The aim of this research was to examine the prevailing drivers of pastoralism and how these are changing. Socioeconomic questionnaires were administered during face-to-face meetings to record household data (age, gender, village of residence, household size, and household income) and herd data (number of livestock, production and use of livestock products, livestock sales, livestock prices, and livestock-based revenue). These data were used to indirectly evaluate the economic importance of pastoralism. Semistructured interviews were used to obtain more detailed qualitative accounts of the drivers of pastoralism. Interviewees were asked about why they keep livestock and the problems

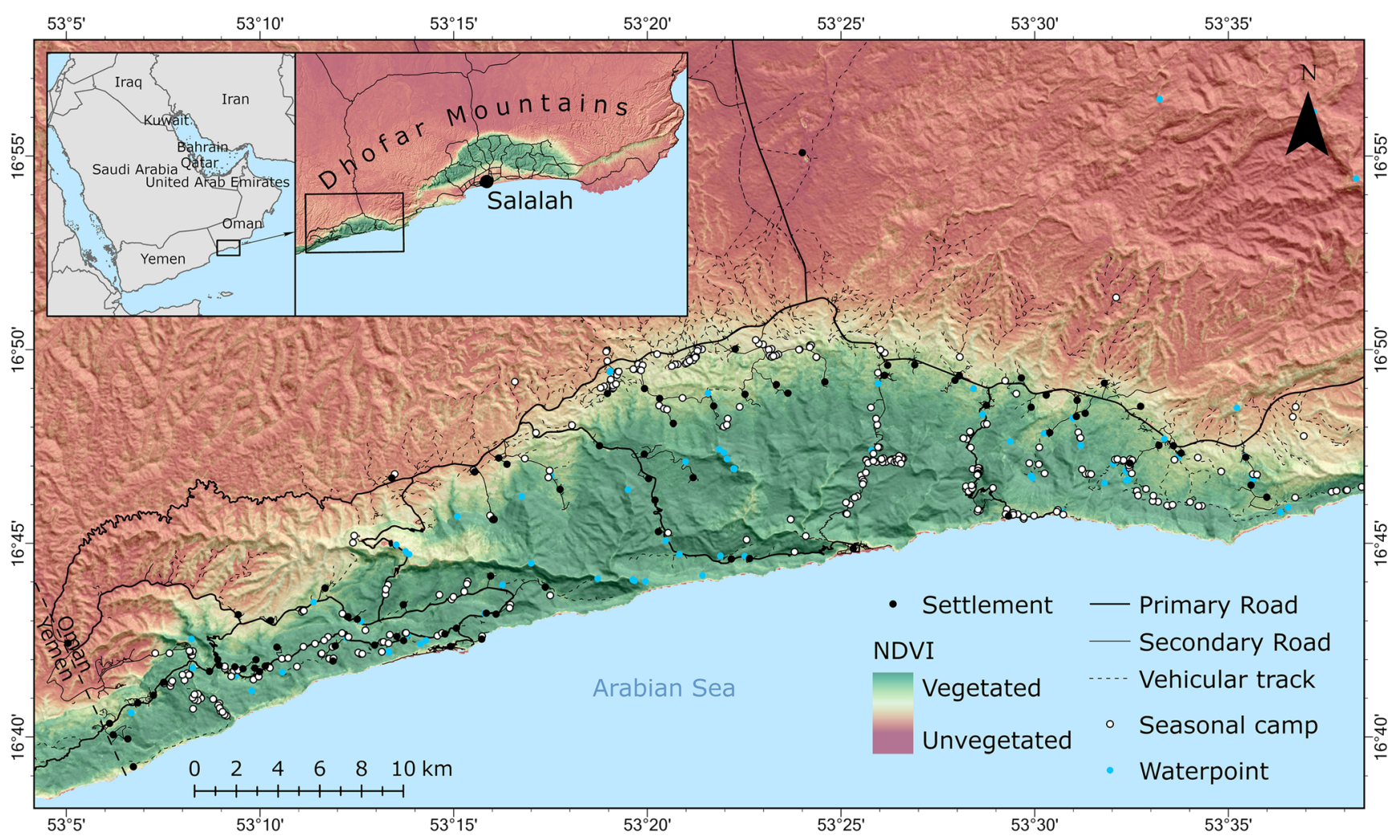

Fig. 1 Map of Jabal Qamar showing locations of settlements, seasonal camps, waterpoints, roads and vehicular tracks, overlaid on a vegetation greenness (NDVI) base map. Two inset maps show the whole Dhofar Mountains and their location in Oman 
Fig. 2 A three-dimensional map showing the three main locations of the transhumance management regime in Jabal Qamar

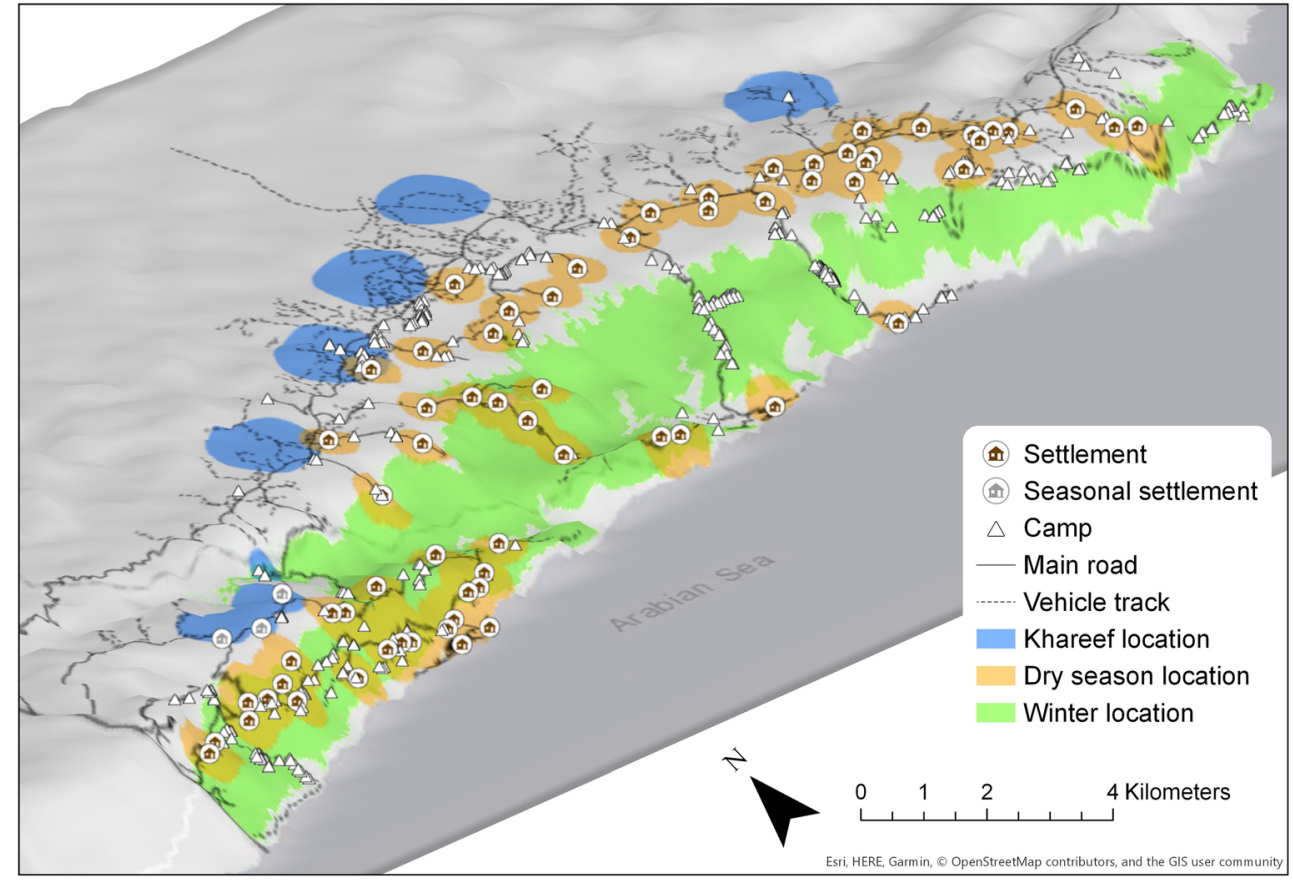

they face with livestock keeping, which stimulated rich discussion on why and how people keep livestock within the contexts of policy, economics, and culture.

In order to obtain a diverse sample we included in our study population any individuals from a household that had previously or currently kept livestock. We used cluster sampling in which villages were randomly selected from settlement areas. Simple random sampling was then used to select households to visit. Efforts were made to sample a greater number of households in large villages, known as probability proportional to size (Newing 2011). Seven of the 84 interviews were referrals (snowball sampling) where an informant encouraged the research team to speak with friends or family, and 26 were opportunistic when individuals were encountered away from households; for example, when herding or doing husbandry.

Interviews were usually conducted with the male head of the household or another male closely involved in livestock keeping. However, some boys and expatriate workers were also interviewed and approximately $10 \%$ of the interviews were conducted with between two and ten interviewees. Few females were interviewed due to the cultural barriers of speaking with females and because of their limited involvement in livestock keeping.

Upon meeting with informants, the aims of the study were explained, and informed consent was sought. Participants were assured that their responses would be confidential and anonymous. Ethical considerations followed the guidelines of the American Anthropological Association (AAA). Interviews with young people (ages 14-17) followed the guidelines of the World Association of Opinion and Marketing Research Professionals (ESOMAR).
The slow pace of the interviews due to translation meant the research assistant could transcribe interview responses. An inductive approach to coding was used. As the research period progressed top level, secondary, and tertiary codes were assigned to the themes in the qualitative data (Newing 2011). Themes of interest with conflicting responses or with unexplained phenomena were revisited with future informants until saturation was reached.

\section{Results}

Here we present our findings on the drivers of pastoralism in the Jabal Qamar mountain range in Dhofar. First, we report some descriptive statistics from the questionnaire data. We then summarise the reasons given by pastoralists for keeping livestock and the problems they face, and present our findings on the drivers of pastoralism, including verbatim quotations of interviewees, under four subsections; pastoral values, household economics, markets, and husbandry.

\section{Descriptive Statistics}

Semi-structured interviews were conducted with 82 men and 2 women (aged between 14 and 80 years) at 84 households in 37 villages (45\% of villages) in Jabal Qamar. Socioeconomic questionnaires were completed with 66 men and 6 women (aged between 23 and 80 years) at 72 households in 21 villages (25\% of villages) in Jabal Qamar. Fifty-nine people were both interviewed and completed questionnaires. Out of all respondents and interviewees, $81 \%$ owned camels, 91\% 
owned cattle, $36 \%$ owned goats, and $2 \%$ did not own livestock. Camel herd sizes ranged from 1 to 200 (median $=27$, interquartile range $=15-40$, mean $=31.7 \pm \mathrm{SE} 2.29$ ), cattle herd sizes ranged from 3 to 250 (median $=35$, interquartile range $=20-50$, mean $=41.1 \pm \mathrm{SE} 2.5)$ and goat herd sizes ranged from 1 to 300 (median $=25$, interquartile range $=15$ 41.5, mean $=38.85 \pm$ SE 5.9).

A Spearman's rho found no significant correlation between interviewee age $\left(r_{s}=-0.11, p=0.133\right)$ and herd sizes. KruskalWallis tests found herd sizes did not differ significantly with household size for individual livestock types (camel: $(H(2)=$ $4.8, \mathrm{p}=0.089)$; cattle: $(H(2)=5.2, \mathrm{p}=0.073)$; goats: $(H(2)=$ $4.3, \mathrm{p}=0.114)$, however for total livestock, small households had significantly fewer livestock than medium and large households $(\mathrm{H}(2)=14.3, \mathrm{p}=<0.001)$. A chi-squared test found a significant positive relationship between household size and household income $(\mathrm{X} 2(4, \mathrm{~N}=73)=15.536, \mathrm{p}=$ 0.004) and Spearman's rho found a significant positive relationship between herd size and number of livestock sold per year (camels: $r_{s}=0.61, p<0.001$, cattle: $r_{s}=0.35, p=0.004$, goats: $\left.r_{s}=0.65, p<0.001\right)$. However, no significant relationship was found between household income and herd sizes.

\section{Motivations and Challenges for Pastoralism}

Pastoralists' reasons for keeping livestock, in order of importance, were: (1) inherited from parents; (2) financial security; and (3) products for the household. These will be discussed in greater detail below.

Pastoralists ranked the bark-stripping behaviour of their camels and cattle as the greatest problem they faced. Many pastoralists believe the concentrated pellet feed contains chemicals that cause bark stripping and aggressive behaviour. To limit damage to trees, many pastoralists remove the front teeth of their camels. Based on a review by Nicodemo and Porfírio-da-Silva (2018) of bark stripping by cattle, this behaviour is most likely associated with low quality pasture.

Pastoralists ranked declines in the abundance and health of vegetation as the second-greatest problem they faced. Almost all informants were aware of recent declines in woody plant cover and grassland productivity. The older generation remember the difference between the past and current vegetation structure of the rangelands in statements such as:

Before 40 years it was like a jungle. You had to climb a tree to see from here to over there.

and:

"Xfot [the shrub Blepharispermum hirtum] used to be everywhere here. Now it is very sparse. Before you could not pass through this area because it was like a fence. Further West there is more but it is still very damaged."

Most pastoralists agree overstocking is the cause of vegetation declines, while decreasing khareef intensity and/or caterpillars were occasionally mentioned. One informant stated:

"Camels are the main cause of desertification. People

like them more than other animals."

while another explained:

"We care about the environment and realise the solution is to keep less animals, but we want to keep animals."

Pastoralists ranked the high cost of feedstuffs as the thirdgreatest problem they faced, which we will discuss in detail later. Other problems included: (4) reduced vegetation regeneration due to progressively weakening khareef intensity; (5) land-use change in rangelands for roads, housing, and other development; and (6) damage to rangeland vegetation from off-road driving.

\section{Pastoral Values}

The primary reason for keeping livestock, which was given by all informants, was due to the inheritance of livestock from parents. Only a few people immediately sell the livestock they inherit from their parents and in our sample no one had done so. Familial pastoral values are also passed down through the generations. These values are learned through everyday activities, for example, when children help their elders with husbandry. These pastoral values are portrayed at the individual level as an overwhelming fondness for livestock keeping and over $70 \%$ of questionnaire respondents agreed that they would like to keep more livestock. Their pastoral values were apparent in their narratives:

"I spend $70 \%$ of my time with my animals and the other $30 \%$ of my time thinking about my animals. From sunrise to sunset, 12 hours, I am with my animals."

and:

"I want my camels more than a massive company. I have forgotten about women and children. Camels are my family."

However, these pastoral values were not universally shared within the population. They are strongest amongst members of the older generation who in the past relied on livestock for sustenance and travel. Several younger informants stated that there is a misconception amongst the older generation that 
livestock still have an important use today. One informant explained:

"Before 40 years the animals were useful. This idea is still in people's minds despite modernisation of the country."

Most children are also passionate about livestock keeping, especially young men who helped their elders with livestock husbandry at home, which was common practice $(87 \%$ or 53 households). However, fewer believed their children would continue to keep livestock in the future (68\% or 56 households). Interviewees explained that some young adults who attend college or university and some adults with tertiary education are losing interest in livestock keeping.

Several informants explained that some people keep livestock to respect their family's pastoral values but are not as committed to pastoralism themselves. One informant stated:

"Every year it is getting more and more expensive. [...] People lose more money than they are making. Only thing that is good is milk. People keep them just to respect parents and grandparents."

Another explained:

"In the last 10 years the old people have been dying in [the village of] Eirkab and with the old people gone, people have been selling their livestock."

Several interviewees admitted they would prefer not to keep livestock at all but are reluctant to sell their livestock out of fear of being perceived by others as weak and disrespectful of their family's pastoral values. Our translator's family had recently sold all their livestock and he admitted that although people do talk, the financial and time benefits outweigh the 'loss of face.' In some instances, pastoralists sold their livestock and then bought them back, as one informant explained:

"Young people hate animals. They don't want to have them. But if they sell them, then people will talk. For example, they might sell 10 camels for 10,000 OMR, but then people start talking, and so they buy them back for double the price. Some people don't care about people talking, but others do. Some sell up and move to Salalah."

\section{Household Economics}

Ninety-seven percent ( $\mathrm{n}=57$ households) of questionnaire respondents stated making a net financial loss from owning livestock. Alongside changing values, the high cost of husbandry is affecting pastoralists' commitment to livestock production and was cited as one of the reasons why some households are giving up pastoralism. On the other hand, many informants explained that they would continue to keep livestock no matter what the cost. Others explained that they would reluctantly stop keeping livestock:

"If it becomes too expensive or difficult to keep animals, then of course, we will have to stop keeping animals.

But we want to keep animals."

The greatest cost comes from purchasing feedstuffs for 10 11 months of the year. Concentrated pellet feed costs 5 OMR (\$12.99) per $50 \mathrm{~kg}$ bag, whilst powder feed costs 2.9 OMR (\$7.53) per $30 \mathrm{~kg}$ bag. On average, one camel is fed six $50 \mathrm{~kg}$ bags of pellet feed per month, at a monthly cost of $30 \mathrm{OMR}$ (\$77.94). The quantity of feedstuffs required to sustain livestock herds has increased since the 1970 s as natural forage resources have decreased and the period of abundant forage availability following the khareef has shortened. Other costs include vehicle fuel, water tanks, feed troughs, veterinary care, and expatriate worker salaries.

The greatest annual loss stated in the questionnaire was 48,000 OMR $(\$ 124,692)$. The greatest profit was 18,000 OMR $(\$ 46,759)$, with an overall mean of a loss of 10,433 OMR $(\$ 27,102)$. However, key informants explained that respondents were likely overestimating losses in anticipation of greater financial support from the government. Nonetheless, they explained that annual losses of up to 5,000 OMR $(\$ 12,988)$ are common. Some livestock keepers are in debt to feedstuff retailers, often repaying the debt in livestock. Some livestock keepers spend all, or in excess of, their salary on livestock husbandry. If a family member's salary does not cover livestock expenses, then higher-earning family members will contribute. A young informant from Dalkut explained:

"I give my father money to cover the costs. My father has to spend 800 OMR on livestock each month, but his income is only 400 OMR, so I help to cover the difference. He is spending more than his salary on a hobby. His salary is small, unlike mine as a geologist, which is three times his. I can go to the bank, a livestock owner cannot."

Given that many pastoralists make a loss from livestock ownership it was surprising that financial security was stated as the second reason for keeping livestock. When asked for further details two themes emerged. The first was financial security in case of an unpredictable event, of which the most commonly stated was loss of government employment and salary. This was exacerbated, at the time of the fieldwork, by 
the collapse in oil prices. The second was associated with the sale of multiple animals in one transaction for instant revenue, if for example, a family member requires expensive healthcare or when purchasing or building a house.

\section{Markets}

Pastoralists in Dhofar have been purchasing feedstuffs since the mid-1970s. Feedstuff production by Dhofar Cattle Feed Company (SAOG) has increased from 120,000 metric tonnes per annum when it was founded in 1984 to 400,000 metric tonnes per annum at present (Dhofar Cattle Feed Company (SAOG) 2015). Due to the capital investments made by pastoralists in livestock keeping, both camel and cattle prices are high. They have also increased substantially in recent years. For example, the average sale price of a camel in the year 2000 was 300 OMR (\$779) and in 2017 it was 1000 OMR $(\$ 2,596)$. This is a $232 \%$ increase, which is much greater than inflation $(55 \%)$ over the same period. Due to their high price there has been little commercialisation or marketing of local livestock. Instead, imported livestock and products from Africa and Oceania dominate local and national food markets. One informant explained:

"Somalia to Salalah is easy; two days. People like cheap meat, some like Australian, local people like Dhofari. In Muscat they like cheap meat. Restaurants buy cheap meat to get more profit, and customers want a cheap price. They do not ask if it is local."

The most recent data available on beef production from local cattle is from 2012: 13,863 tonnes of beef products were produced from 87,492 imported head of cattle, but only 1,273 tonnes of beef were produced from the 346,000 head of indigenous cattle produced that year (FAO 2016). It should be noted that there is a low demand for camel meat and therefore camels are not imported for slaughter.

Whilst there are no large-scale markets, beef (and occasionally camel meat) is sold at pop-up locations in rural areas or at the Salalah meat market. Livestock are also traded informally between friends and families. At the time of data collection, pop-up markets in Jabal Qamar accounted for only a small offtake of livestock (1-3 animals) each day. Each day in the town of Shahb Asaayb in Rakhyut, one to three local livestock owners sold meat out of the back of their vehicles. Each morning in Dalkut a Pakistani butcher slaughtered an animal and arranged the meat in to piles to be sold for 20 OMR (\$51.91) for $5 \mathrm{~kg}$ or $4.5 \mathrm{OMR}(\$ 11.68)$ for $1 \mathrm{~kg}$. For comparison, the cost of local-slaughtered Somali boneless beef in a large supermarket in Salalah was 3.59 OMR (\$9.32) for $1 \mathrm{~kg}$. One informant explained that locals prefer the taste, texture and nutritional value of local meat to imported meat.
Our questionnaire results showed that annual camel sales ranged between 0 and 35 animals $($ mean $=5$, mode $=0)$ and annual cattle sales ranged between 0 and 45 animals (mean = 8 , mode $=5$ ). Goats were not regularly sold (mean $=3$, mode $=0$ ), although goat barbeques in the mountains are frequent. In recent years selective breeding of Dhofari goats for appealing traits has become more common. Approximately one third of respondents sold camel or cattle meat, and fewer sold milk (Fig. 3). The home consumption of meat and milk was the most popular use of livestock products (Fig. 3) and was the third and final reason given for keeping livestock. All camel-owning households in our questionnaire sample produced milk from their camels for consumption in the household. One key informant explained that purchasing meat and milk is in fact much cheaper than owning livestock, however the quality of milk varies, and people prefer to consume milk from their own livestock. Indeed, many stressed the health benefits of camel milk afforded to their family and growing children. One individual explained:

"If you go to hospital and have to have an anaesthetic, it is harder to get the needle into someone who has drunk camel milk every day because the muscle is firmer."

\section{Discussion}

Contemporary pastoralism in Jabal Qamar is driven primarily by pastoral values, whilst a long-term store of wealth and products for the household are secondary benefits. Based on our findings, we use the term 'pastoral values' to describe the 'respect for, and inheritance of, the cultural values held by one's parents or ancestors regarding pastoralism.' Such a definition seems transferable to other pastoral societies, such as the Borana pastoralists in Ethiopia, for whom inherited cattle were historically of the highest symbolic, social and economic value (Megersa et al. 2014). The fervour and characteristics of these pastoral values may differ between households and individuals, due to factors such as age, wealth, education, livestock type, and alternative income sources, and can of course change. In Jabal Qamar, some households have recently given up pastoralism due to their changing values and in response to high husbandry costs, a trend also occurring amongst the Borana (Desta and Coppock 2004). The prevalence and nature of these changing pastoral values in Dhofar should be a priority for future research.

Sociocultural factors motivate livestock ownership in pastoral societies across the world, but usually in parallel with income generation or subsistent use. People in Jabal Qamar, however, remain committed to pastoralism due to their pastoral values, despite high husbandry costs. Elsewhere in Oman 
Fig. 3 Percentages of households in the questionnaire survey that produce livestock products for household consumption and sale m Camel $=$ Cattle $n$ Goat

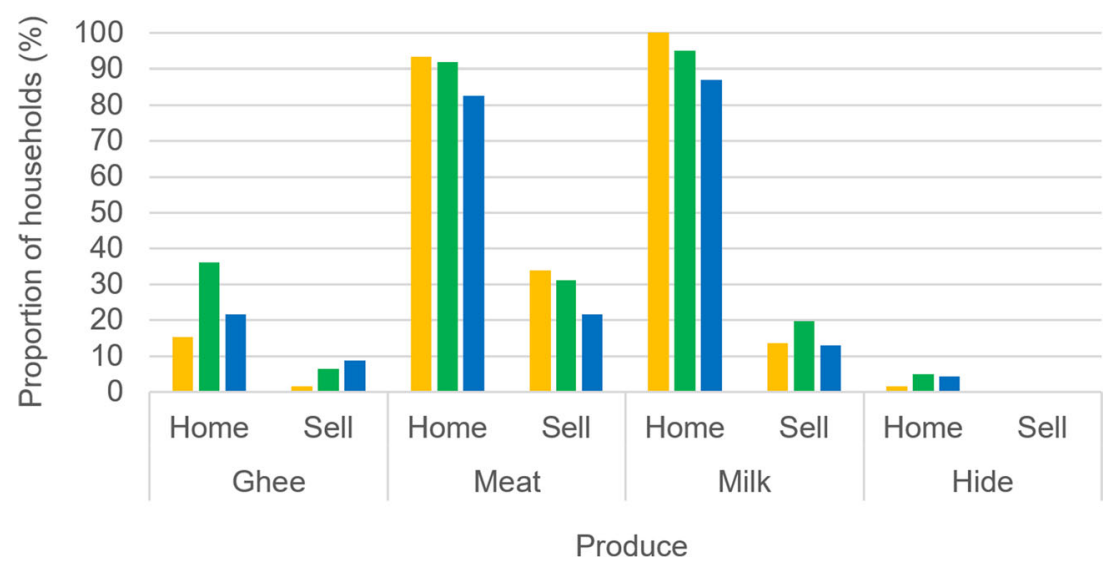

and in other oil rich Gulf nations, pastoralism has evolved into a contemporary 'camel culture' (Khalaf 1999). Camels are kept in fenced pens centred round racetracks rather than food or water sources, and owners have limited involvement in day-to-day husbandry, although capital investment is high. It is likened to a hobby rather than a livelihood (Gallacher 2010). In Dhofar however, livestock keepers are comparatively more involved in husbandry and livestock products are consumed in the household. Camels are bred for their milk rather than racing, and pastoralists also invest in cattle. It appears that for most pastoralists in Jabal Qamar, the enjoyment gained from livestock ownership, coupled with a long-term store of wealth and products for the household, is worth the investments.

Our quantitative results detected variations in socioeconomic and sociocultural factors between households. For example, we found that smaller households have lower incomes and own and sell less livestock. However, we did not detect a significant direct relationship between household income and herd sizes. This makes sense when we consider that livestock production is not profitable, that households have varying amounts of non-livestock income, and that other factors, such as pastoral values, can influence herd sizes and other management decisions.

It should be recognised that this study was limited to Jabal Qamar and thus it may not be representative of all Dhofar. While it is likely that similar factors drive pastoralism in other areas of Dhofar, the perceived problems and pastoral practises may differ. For example, it is very unlikely that bark stripping is the greatest problem perceived by pastoralists in areas of Dhofar dominated by grasslands. Triangulation of our key findings with communities or key informants elsewhere in Dhofar would be valuable.

We found evidence of changing pastoral values and some households have given up pastoralism, but what might this mean for the future of pastoralism in Jabal Qamar? We might see further increases in rural-urban migration to Salalah and/or more rural households giving up pastoralism, especially if husbandry costs increase. We would likely see a gradual departure from the current 'peer pressure' to keep livestock. Traditional ecological knowledge and pastoral culture may be lost with the older generation (Aswani et al. 2018), as has been described amongst Borana pastoralists in Ethiopia (GemedoDalle et al. 2006). Alternatively, pastoralism might evolve into a contemporary 'camel culture', focused on camel competitions (Khalaf 1999). Camel competitions are known to facilitate preservation, evolution, and revival of rangeland culture in Gulf nations (Gallacher 2010; Khalaf 1999). It is interesting to note that in 2012 in Jabal Qamar, local people with help from the private sector established a camel milking competition, which was said to be a new motivation for camel ownership in the last five years. Sustainable intensification of livestock production, incorporating a license system and camel tourism, could be one approach to maintain a rural pastoral economy that contributes to the national and export food markets (El-Mahi 2011a; Tilman et al. 2011). Those with strong pastoral values could participate in a livestock production system that is financially rewarding, while those who no longer want to keep livestock could sell their livestock without 'loss of face.'

Feedstuffs in livestock production systems are considered a global sustainability issue and given the current trend of global livestock sector growth, we may see an increased use of feedstuffs amongst smallholder pastoralists (Herrero et al. 2013; Mottet et al. 2017). The case of Dhofar shows how supplementary feeding can fuel livestock population growth, but it also has implications for concepts in the rangeland sciences. Firstly, regular supplementary feeding can reduce the dependence of livestock and livestock keepers on forage resources (Fig. 4). A low dependence leaves little or no motivation for conservation and masks a requirement for mutual agreement on resource use and self-organization (Ostrom 1990), which has otherwise been shown to sustainably govern rangeland resources in open access systems (Moritz et al. 2013a, b). A reduced dependence on natural forage resources due to supplementary feeding has been described among the Bedu of Jordan (Blench 1995) and the Bedouin of Saudi 
Fig. 4 Conceptual diagram of the drivers (dashed box) of pastoralism and the effects of capital investment by pastoralists

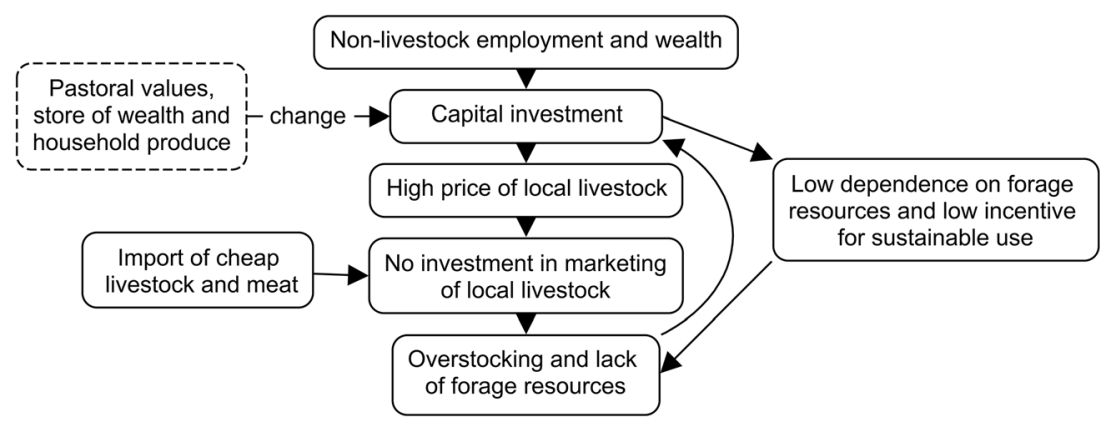

Arabia (Gardner 2004) and can be pinpointed as a key factor in the status quo of overstocking in Dhofar. Secondly, feedstuff provisioning can increase the cost of livestock ownership and the price of livestock and thus may impact local and national livestock market sectors, as well as socioeconomic and political processes at multiple scales. Thirdly, and as previously acknowledged, it enables pastoralists to overcome density-dependent regulation of livestock populations, which is a major factor in defining equilibrium and non-equilibrium rangeland dynamics (Ellis and Swift 1988). Moreover, it can result in rangeland degradation to an extent that is acknowledged by pastoralists themselves, and thus leaves little doubt as to whether the rangelands are overstocked - a question that has challenged rangeland scientists for almost a century (Sayre 2017).

The current unproductive and unsustainable state of pastoralism in Jabal Qamar can be partly attributed to the impacts of governance processes associated with the economic development of the Dhofar region on sociocultural processes at the household level. Pastoralists have remained committed to livestock production, but the pastoral system has been shaped by external economic and market factors outside the control of local pastoralists. This is exemplified when we look at where investments have been made in pastoralism. Early infrastructural development in rural areas, such as roads, dams, and watering troughs focused on supporting pastoralism, and livestock numbers increased. Simultaneously, employment of rural peoples by the government was in jobs outside of pastoralism, but incomes were invested in livestock, and livestock numbers increased. Increased wealth meant market participation was a low priority for pastoralists and no entrepreneurship or collective action took place (Ostrom 2007). Subsidized feedstuffs were manufactured and distributed to rural areas, enabling pastoralists to overcome the density-dependent regulation of livestock populations, and livestock numbers increased. Yet there was little off take of livestock. Government efforts to reduce livestock numbers, including purchasing yearling cattle for slaughter (1970s), animal tagging and herd size limits, and destocking programs in 19831989 and 2000-2003 (UNEP 2005), had a negligible impact on inhibiting overall livestock population growth. Furthermore, there was no investment in production and marketing of local livestock, and it was cheaper to import livestock and products from abroad (Fig. 4). As Gardner (2004) wrote with regards to Bedouin in Saudi Arabia, "the herders' increasing dependency on imported feedstuffs enmeshed them in a political economy driven by both regional and global dynamics."

\section{Conclusions}

Pastoralism in the Jabal Qamar mountain range in Dhofar is motivated by familial pastoral values, whilst livestock also offer a long-term store of wealth and livestock products for the household. Economic and market factors linked to the development of the Dhofar region, and increased wealth amongst pastoralists, has led to high capital investment by pastoralists in feedstuffs. This has enabled pastoralists to overcome the density-dependent regulation of livestock populations, and stakeholders are concerned about the ecological impacts of overstocking. Capital investment by pastoralists means local livestock prices are high and there has been little investment in marketing and commercialization of the local livestock sector. Our study shows how pastoral values persist as a critical driver of pastoralism in the face of globalization, modernisation, social change, and despite high husbandry costs, although pastoral values are changing and some households in Jabal Qamar are giving up pastoralism. If this trend continues, we may see less extensive pastoralism, and in the case of camels, a shift to a contemporary 'camel culture,' as seen elsewhere in Arabia.

Acknowledgements The authors wish to thank the pastoralists who participated in this study and Alana Ball, Ali Bawazir, Khalid Bawazir, Dr Israr Ul Hassan and Dr Mohamed Limam for their assistance with the fieldwork.

Funding Information This work was funded by the UK Economic and Social Research Council (award reference 1595870), the US National Science Foundation (grant number BCS-1617185) and the AngloOmani Society, UK, with logistical support from Dhofar University.

Data Availability The datasets from this study are available from the corresponding author on reasonable request. 


\section{Compliance with Ethical Standards}

Conflict of Interest The authors declare that they have no conflicts of interest.

Open Access This article is licensed under a Creative Commons Attribution 4.0 International License, which permits use, sharing, adaptation, distribution and reproduction in any medium or format, as long as you give appropriate credit to the original author(s) and the source, provide a link to the Creative Commons licence, and indicate if changes were made. The images or other third party material in this article are included in the article's Creative Commons licence, unless indicated otherwise in a credit line to the material. If material is not included in the article's Creative Commons licence and your intended use is not permitted by statutory regulation or exceeds the permitted use, you will need to obtain permission directly from the copyright holder. To view a copy of this licence, visit http://creativecommons.org/licenses/by/4.0/.

\section{References}

Aswani, S., Lemahieu, A., and Sauer, W. H. H. (2018). Global trends of local ecological knowledge and future implications. PLoS One 13(4):e0195440.

Ball, L., and Tzanopoulos, J. (2020). Livestock browsing affects the species composition and structure of cloud forest in the Dhofar Mountains of Oman. Applied Vegetation Science 00:1-14.

Blench, R. (1995). Rangeland degradation and socio-economic changes among the Bedu of Jordan: results of the 1995 IFAD survey. Pastoral Development Network \& Overseas Development Institute, London.

Chatty, D. (2006). Nomadic societies in the Middle East and North Africa: entering the 21st century. Brill Academic Publishers, Leiden.

Chatty, D. (2013). From Camel to Truck: the Bedouin in the Modern World. (2nd ed.), Vantage Press, New York.

Degen, A. A., El-Meccawi, S., and Kam, M. (2019). The Changing Role of Camels among the Bedouin of the Negev. Human Ecology 47(2): 193-204.

Desta, S., and Coppock, D. L. (2004). Pastoralism under pressure: Tracking system change in Southern Ethiopia. Human Ecology 32(4): 465-486.

Dhofar Cattle Feed Company (SAOG). (2015). Brief History. Accessed: 8th October 2019 http://www.dhofarcattlefeed.om/pages/8.

Directorate-General of Nature Conservation. (2010). Fourth National Report To the Convention on Biological Diversity. Ministry of Environment and Climate Affairs, Muscat.

El-Mahi, A. T. (2011a). Old ways in a changing space: the issue of camel pastoralism in Dhofar. Sultan Qaboos University Journal Agricultural and Marine Sciences 16: 51-64.

El-Mahi, A. T. (2011b). Hematophagous Flies in Dhofar (Sultanate of Oman): A Limiting Factor and a Potential Pathogenic Vector. Sultan Qaboos University Journal - Agricultural and Marine Sciences 16: 65-73.

Ellis, J. E., and Swift, D. M. (1988). Stability of African Pastoral Ecosystems: Alternate Paradigms and Implications for Development. Journal of Range Management 41(6): 450.

FAO. (2016). FAOSTAT database collections. Rome Accessed: 8th October $2019 \mathrm{http}: / / \mathrm{www}$. faostat.fao.org/.

Faye, B. (2014). The Camel Today: Assets and Potentials. Anthropozoologica 49(2): 167-176.

Friesen, J., Zink, M., Bawain, A., and Müller, T. (2018). Hydrometeorology of the Dhofar cloud forest and its implications for groundwater recharge. Journal of Hydrology: Regional Studies 16: 54-66.

Gallacher, D. J. (2010). Arid rangeland degradation in an oil-rich Gulf state; inertia of perceived heritage and pro-agricultural policies. In Veress, B. and Szigethy, J. (Eds.),Horizons in Earth Science Research (Vol. 1). Nova Science Publishers, New York.

Gardner, A. (2004). The New Calculus of Bedouin Pastoralism in the Kingdom of Saudi Arabia. Political Ecology Across Spaces, Scales, and Social Groups 62(3): 267-276.

Gemedo-Dalle, Isselstein, J., and Maass, B. L. (2006). Indigenous ecological knowledge of Borana pastoralists in southern Ethiopia and current challenges. International Journal of Sustainable Development and World Ecology 13(2): 113-130.

GRM International. (1982). Range and Livestock Survey. G.R.M. International Pty Ltd., Brisbane.

Hamadeh, S. (2014). Livestock and Food Security. In Sadik, A.-K., ElSolh, M., and Saab, N. (eds.), Arab Environment 7: Food Security Challenges and Prospects. Beirut, AFED, Lebanon.

Herrero, M., Havlik, P., Valin, H., Notenbaert, A., Rufino, M. C., Thornton, P. K., Blummel, M., Weiss, F., Grace, D., and Obersteiner, M. (2013). Biomass use, production, feed efficiencies, and greenhouse gas emissions from global livestock systems. Proceedings of the National Academy of Sciences 110(52): 20888-20893.

Hildebrandt, A., and Eltahir, E. A. B. (2006). Forest on the edge: Seasonal cloud forest in Oman creates its own ecological niche. Geophysical Research Letters 33(11): 2-5.

Janzen, J. (1990). Land Tenure and Land Use in the Pastoral Living Areas of Dhofar, Sultanate of Oman. FAO, Rome.

Janzen, J. (2000). The destruction of resources among the mountain nomads of Dhofar. In Mundy, M. and Basim, M. (eds.), The Transformation of Nomadic Society in the Arab East. Cambridge University Press, Cambridge.

Khalaf, S. (1999). Camel racing in the Gulf. Notes on the Evolution of a Traditional Cultural Sport. Anthropos 94(1): 85-106.

Kürschner, H., Hein, P., Kilian, N., and Hubaishan, M. A. (2004). The Hybantho durae-Anogeissetum dhofaricae ass. nova Phytosociology, structure and ecology of an endemic South Arabian forest community. Phytocoenologia 34(4): 569-612.

Louhaichi, M., and Tastad, A. (2010). The Syrian steppe: Past trends, current status, and future priorities. Rangelands 32(2): 2-7.

Megersa, B., Markemann, A., Angassa, A., Ogutu, J. O., Piepho, H. P., and Valle Zárate, A. (2014). Livestock Diversification: An Adaptive Strategy to Climate and Rangeland Ecosystem Changes in Southern Ethiopia. Human Ecology 42(4): 509-520.

Moritz, M., Catherine, L. B., Drent, A. K., Kari, S., Mouhaman, A., and Scholte, P. (2013a). Rangeland governance in an open system: Protecting transhumance corridors in the Far North Province of Cameroon. Pastoralism 3(26):1-10

Moritz, M., Scholte, P., Hamilton, I. M., and Kari, S. (2013b). Open Access, Open Systems: Pastoral Management of Common-Pool Resources in the Chad Basin. Human Ecology 41: 351-365.

Mottet, A., de Haan, C., Falcucci, A., Tempio, G., Opio, C., and Gerber, P. (2017). Livestock: On our plates or eating at our table? A new analysis of the feed/food debate. Global Food Security 14: 1-8.

NCSI. (2017). 2017 Statistical Year Book. National Centre for Statistics and Information, Muscat.

Newing, H. (2011). Conducting Research in Conservation: A Social Science Perspective. (1st ed.). Routledge, Abingdon.

Nicodemo, M. L. F., and Porfírio-da-Silva, V. (2018). Bark stripping by cattle in silvopastoral systems. Agroforestry Systems 93(1): 305315.

Nyberg, G., Knutsson, P., Ostwald, M., Öborn, I., Wredle, E., Otieno, D. J., et al. (2015). Enclosures in West Pokot, Kenya: Transforming land, livestock and livelihoods in drylands. Pastoralism 5(1). 
Ostrom, E. (1990). Governing the Commons: The Evolution of Institutions for Collective Action. (14th ed.), Cambridge University Press, Cambridge.

Ostrom, E. (2007). A diagnostic approach for going beyond panaceas. Proceedings of the National Academy of Sciences. 104(39): 1518115187.

Peacock, J.., Ferguson, M. ., Alhadrami, G. A., McCann, I. R., Al Hajoj, A., Saleh, A., and Karnik, R. (2003). Conservation through utilization: a case study of the indigenous forage grasses of the Arabian Peninsula. Journal of Arid Environments 54: 15-28.

Petraglia, M. D., and Rose, J. I. (2010). The Evolution of Human Populations in Arabia. New York: Springer.

Robinson, T. P., Thornton, P. K., Franceschini, G., Kruska, R. L., Chiozza, F., Notenbaert, A., Cecchi, G., Herrero, M., Epprecht, M., Fritz, S., You, L., Conchedda, G., and See, L. (2011). Global livestock production systems. FAO \& ILRI, Rome.

Sayre, N. F. (2017). The Politics of Scale: A History of Rangeland Science. University of Chicago Press, Chicago.

Sayre, N. F., McAllister, R. R., Bestelmeyer, B. T., Moritz, M., and Turner, M. D. (2013). Earth Stewardship of rangelands: Coping with ecological, economic, and political marginality. Frontiers in Ecology and the Environment 11(7): 348-354.

Sidahmed, A. E. (1992). Sustainable Rangelands in the Near East and North Africa. Rangelands 14(4): 201-205.

Spalton, A. (2020). Agriculture [Jabal Al Qara]. In Al Zubair, M., Mershen, B., Al Saqri, S., Al Ghafri, A., Al Hosni, T., Al
Nabhani, Y., Al Rajhi, A., Nasir, S., Patzelt, A., Spalton, A., and Anderson, A. (Eds.), The Mountains of Oman. Georg Olms AG, Hildesheim.

Tilman, D., Balzer, C., Hill, J., and Befort, B. L. (2011). Global food demand and the sustainable intensification of agriculture. Proceedings of the National Academy of Sciences 108(50): 20260-20264.

UNEP. (2005). National Action Programme to Combat Desertification in the Sultanate of Oman. Ministry of Regional Municipalities Environment and Water Resources \& UNEP \& UNCCD, Muscat.

Watson, E. E., Kochore, H. H., and Dabasso, B. H. (2016). Camels and Climate Resilience: Adaptation in Northern Kenya. Human Ecology 44(6): 701-713.

Whitcombe, R. P. (1998). Botany, environment and planning in drylands. In Prendergast, H, D, V., Etkin, N, I., Harris, D, R., and Houghton, P, J. (eds.), Plants for Food and Medicine, Royal Botanic Gardens, Kew, London.

WS Atkins International. (1990). Subregional land use plans for the Southern Region, Final Report, March 1990. WS Atkins International \& Planning Committee for Development and Environment in the Southern Region (PCDESR), Epsom.

Publisher's Note Springer Nature remains neutral with regard to jurisdictional claims in published maps and institutional affiliations. 